\title{
Transdifferentiation of pancreatic cells by loss of contact-mediated signaling
}

\author{
Walter de Back ${ }^{1}$, Roland Zimm ${ }^{1,2}$ and Lutz Brusch ${ }^{1 *}$
}

\begin{abstract}
Background: Replacement of dysfunctional $\beta$-cells in the islets of Langerhans by transdifferentiation of pancreatic acinar cells has been proposed as a regenerative therapy for diabetes. Adult acinar cells spontaneously revert to a multipotent state upon tissue dissociation in vitro and can be stimulated to redifferentiate into $\beta$-cells. Despite accumulating evidence that contact-mediated signals are involved, the mechanisms regulating acinar-to-islet cell transdifferentiation remain poorly understood.
\end{abstract}

Results: In this study, we propose that the crosstalk between two contact-mediated signaling mechanisms, lateral inhibition and lateral stabilization, controls cell fate stability and transdifferentiation of pancreatic cells. Analysis of a mathematical model combining gene regulation with contact-mediated signaling reveals the multistability of acinar and islet cell fates. Inhibition of one or both modes of signaling results in transdifferentiation from the acinar to the islet cell fate, either by dedifferentiation to a multipotent state or by direct lineage switching.

Conclusions: This study provides a theoretical framework to understand the role of contact-mediated signaling in pancreatic cell fate control that may help to improve acinar-to-islet cell transdifferentiation strategies for $\beta$-cell neogenesis.

Keywords: Lineage conversion, Intercellular communication, Reprogramming, Pancreas, Acinar cells, Islet cells, Mathematical model, Multicellular systems biology

\section{Background}

In the course of embryonic development, cells become progressively more specialized. Yet, it is becoming increasingly clear that adult differentiated cells retain the ability to change cell fate under certain conditions $[1,2]$. Novel approaches in regenerative medicine aim at harnessing this cell type plasticity in order to replace diseased or damaged tissue by targeted conversion of cells from other tissues [3]. Transdifferentiation, also known as lineage conversion, from one cell type to another often involves a dedifferentation step to reinstate multipotency, but it is also possible to force cells to switch lineages directly [4]. Cells can be reprogrammed by ectopic expression of specific transcription factors using viral transduction $[5,6]$. However, some cell types can also be converted without genetic manipulation, by

\footnotetext{
*Correspondence: lutz.brusch@tu-dresden.de

${ }^{1}$ Center for Information Services and High Performance Computing,

Technische Universität Dresden, Dresden, 01062, Germany

Full list of author information is available at the end of the article
}

merely changing the cellular microenvironment. For many purposes, microenvironment-induced conversion may be preferable since it avoids the risks of random viral integration [7]. Contact-mediated signals from neighboring cells constitute a major part of the cellular microenvironment and recent studies have highlighted the importance of cellcell contacts and surface-bound signals for pluripotency and cell type stability [8-14]. Yet, little is known about the regulatory effects of contact-mediated signals on cell fate stability and cell type conversion. In this paper, we investigate the role of contact-mediated signaling mechanisms in transdifferentiation by a theoretical study of cell fate control in the pancreas.

The pancreas is an organ with dual exocrine/endocrine functions. Acinar cells produce digestive enzymes that enter into the gut, whereas $\alpha$ and $\beta$-cells, organized in the islets of Langerhans, release hormones into the blood stream for glucose homeostasis. Disruption of this homeostasis in diabetic patients is caused by a loss of functional $\beta$-cells. Conversion of cells from other pancreatic tissues 
into new $\beta$-cells has been proposed as a replacement therapy [15]. Acinar cells are interesting candidates as a source for transdifferentiation because of the common developmental origin of exocrine and endocrine cells as well as the abundance of acinar cells in the pancreas [16]. In fact, reprogramming of acinar cells into new $\beta$-cells has already been demonstrated in vivo in mice using ectopic expression of key transcription factors using viral transduction [17]. Intriguingly, such transdifferentiation has also been demonstrated in in vitro cultures without genetic manipulation, using only microenvironmental changes [18-21]. These studies show that adult acinar cells spontaneously dedifferentiate upon loss of cell-cell contacts by enzymatic tissue dissociation. Transcription factors and signaling pathways such as Notch signaling are reactivated which normally are only expressed during development. These progenitor-like cells can be converted into $\beta$-cells, although the yield is typically very low [19-22]. Interestingly, it has been found that the efficiency of lineage conversion can be improved dramatically by inactivation of Notch signaling [23].

These findings suggest that at least two contactmediated or lateral signaling pathways are involved in acinar-to- $\beta$-cell conversion. First, dedifferentiation seems to be controlled by the loss of a stabilizing signal that is mediated by contact with adjacent acinar cells and is required for the maintenance of the acinar identity [16]. Second, redifferentiation into the endocrine lineage of islet cells seems to be hampered by contact-mediated Notch signaling [23] in a mechanism known as lateral inhibition, as previously described for pancreas development [24]. Understanding how these lateral signaling pathways act together in regulation of cell type stability and conversion dynamics can be an important step towards the development of non-genetic methods of $\beta$ cell neogenesis.

In this study, we construct and analyze a mathematical model that combines gene regulation with two contactmediated signaling mechanisms: lateral inhibition and lateral stabilization. Using a combination of bifurcation analysis and numerical simulation, we find that multistability of gene expression states underlies the potential of acinar-to-islet cell conversion. Whereas loss of lateral stabilization causes a step-wise conversion through a multipotent progenitor-like state, additional loss of lateral inhibition induces the direct transdifferentiation from acinar to islet cells. In addition, cell density as well as the size and structure of cellular aggregates are found to affect the efficiency of conversion. Our results demonstrate that the combination of two lateral signaling mechanisms suffices to reproduce observations of acinar-to-islet cell conversion. By clarifying the role of lateral signals in lineage conversion, this new theoretical framework may contribute to improving strategies of microenvironment- induced transdifferentiation in general and to $\beta$-cell neogenesis in particular.

\section{Methods}

Gene regulatory networks can be mathematically modeled and analyzed in terms of differential equations [25]. This can help to understand the complex feedback mechanisms underlying cell fate control [26]. By means of model analysis, one can reveal the existence of attractors that represent cellular phenotypes and understand the dynamics between states [27-29]. Using such a systems biological approach, we have previously shown that the results of genetic reprogramming experiments in the pancreas can be predicted from the hierarchical topology of the underlying gene regulatory network [30]. In the present study, we construct a minimal model of the gene regulatory network and contact-mediated signaling pathways underlying endocrine/exocrine cell fate decisions and maintenance in the pancreas and analyse this model using a combination of bifurcation analysis and tissue-scale lattice simulation.

The state of each cell is specified by four variables, $A, X, Y, Z$ representing the expression levels of key transcription factors. Whereas $X$ and $Y$ correspond to core fate-determining genes and are involved in contactmediated signaling, the factors $A$ and $Z$ represent upand downstream factors (see Figure 1). More specifically, the factor $X$ represents the pro-endocrine transcription factor Ngn3 that is transiently expressed during early pancreas development and participates in Notch-mediated lateral inhibition [24,31]. Ngn3 activates the expression of the membrane-bound Notch ligand Delta-like1 (Dll1) [24]. Reversely, activated Notch signaling causes inhibition of Ngn3 by the transcriptional repressor Hes1 [32]. As a result, neighboring cells compete for endocrine commitment by mutual inhibition of $N g n 3$ expression, in a mechanism called lateral inhibition [33,34]. The factor $Z$ represents a terminal endocrine fate marker downstream of Ngn3 such as Isl1 [31,35] that, once induced, retains its expression by positive auto-activation. As an islet cell maturation factor, it acts to repress the expression of upstream factor $A$.

The factor $Y$ is interpreted as Ptfla, which is the only transcription factor known to be necessary and sufficient to induce the exocrine cell fate [36,37], but is expressed in all pancreatic progenitor cells [38]. Based on experimental evidence that adult acinar cells lose Ptfla expression upon loss of physical cell-cell contact [16,18-21], we assume that factor $Y$ is involved in lateral stabilization. Lateral stabilization provides a positive feedback loop between $Y$-expressing neighboring cells [39]. The rate of $Y$ production is up-regulated by its simultaneous expression in neighboring cells. Mathematically, this is represented by a multiplication, such that non- $Y$-expressing cells do not 


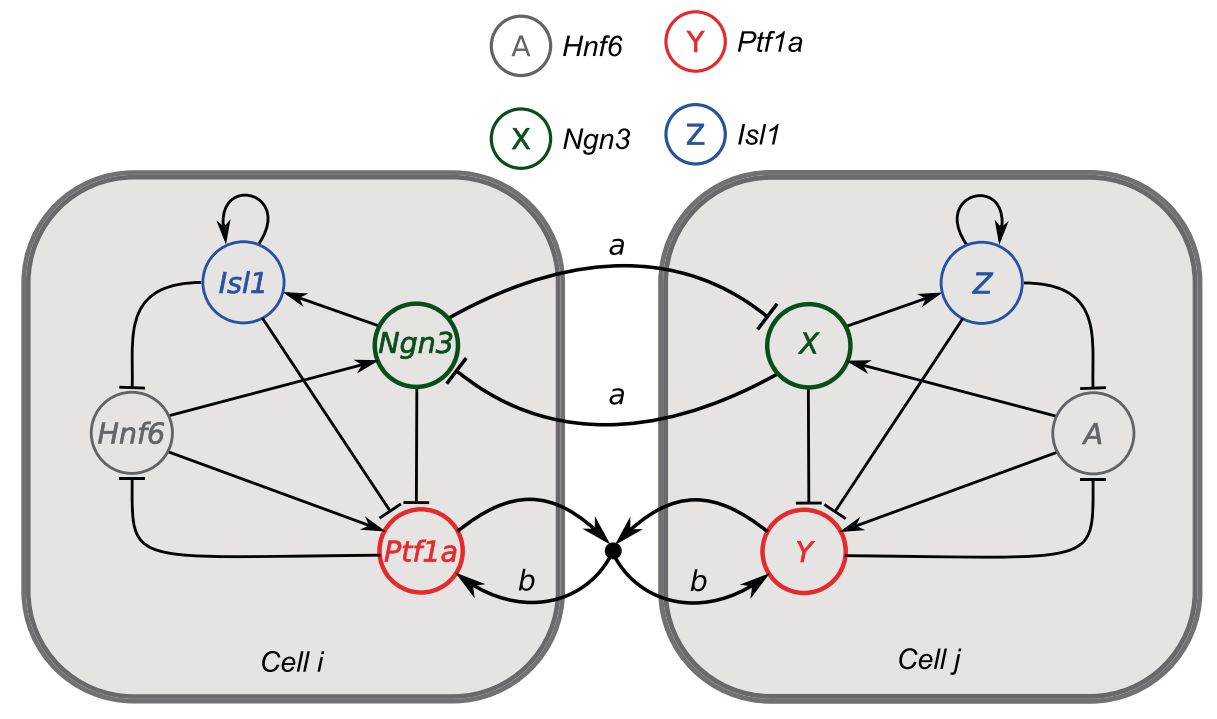

Figure 1 Gene regulation and lateral signaling network. In cell $i$, the common names of the transcription factors are used. In cell $j$, these are replaced by the respective model variables. Cells $i$ and $j$ are coupled by lateral inhibition of factors $X$, and by lateral stabilization between factors $Y$. For each cell, the upstream factor $A$ induces expression of $X$ and $Y$, while $X$ also induces $Z$ expression, which activates itself. Both endocrine factors $X$ and $Z$ antagonize exocrine factor $Y$. Once differentiated, the markers $Y$ and $Z$ down-regulate $A$. Parameters in small lower case represent strengths of the interactions.

participate in lateral stabilization. Although the molecular details of a lateral stabilization pathway are unclear, such conditional activation is, in principle, consistent with both cadherin/beta-catenin signaling [13] as well as with Mist1-mediated gap junctional communication [14]. In both cases, cells need to express monomeric proteins that form homotypic transmembrane complexes in order to signal to adjacent cells.

Although the endocrine and exocrine markers are mutually exclusive [40], the underlying regulatory mechanisms remain unresolved. One model holds that $N k \times 6.1$, a pro-endocrine factor downstream of Ngn3 [41,42], antagonizes the expression of Ptfla [43]. Independent of the precise molecular pathway, we assume that (pro-) endocrine factors $X$ and $Z$ independently suppress the expression of $Y$ leading to the restriction of the latter factor to the exocrine compartment.

Both Ngn3 and Ptf1a are known to be induced by the upstream factor $H n f 6$, either directly [44] or indirectly $[45,46]$. To reflect this fact in the model, factor $A$ induces the expression of $X$ and $Y$. Both $H n f 6$ and Ngn3 are downregulated during late developmental stages and are not expressed in the adult pancreas under normal circumstances [31]. In the model, this is captured by negative feedback of the terminal islet and acinar markers, $Z$ and $Y$, on the inducing factor $A$. Indirectly, this also causes the down-regulation of $X$.

These gene-gene and cell-cell interactions can be formulated in terms of the following system of stochastic differential equations using Hill kinetics (parameters as in Table 1):

$$
\begin{aligned}
\frac{d A}{d t} & =\frac{1}{1+r Y^{n}+r Z^{n}}-A \\
\frac{d X}{d t} & =\frac{q A^{n}}{q+a \bar{X}^{n}}-X+\xi_{x}(t) \\
\frac{d Y}{d t} & =\frac{q A^{n}+b(Y \bar{Y})^{n}}{q+b(Y \bar{Y})^{n}+c X^{n}+c Z^{n}}-Y+\xi_{y}(t) \\
\frac{d Z}{d t} & =\frac{X^{n}+s Z^{n}}{1+s Z^{n}}-Z
\end{aligned}
$$

The terms $\bar{X}$ and $\bar{Y}$ denote the average expression of $X$ and $Y$ in the directly adjacent neighboring cells. To implement lateral inhibition, production of $X$ is inhibited by the expression of $X$ in neighboring cells, $a \bar{X}^{n}$, independent of its own activation. In contrast, the multiplicative term representing lateral stabilization, $b(Y \bar{Y})^{n}$, acts to stabilize a pre-existing expression. This requires the cell-autonomous activity of $Y$ in both cells.

The additive stochastic terms $\xi(t)$, accounting for variability in gene expression or signaling noise, are random variables with a Gaussian white noise distribution $N(0, \eta)$ with mean 0 and amplitude $\eta$. The Hill coefficient $n$ is chosen such that the system exhibits non-linear step-like behavior $(n=3)$. The model variables are scaled in such a way that the steady state expression of all factors is between 0 and 1 . Parameter values are chosen such that the acinar cell fate (cells with $Y \approx 1$ ) and islet cell fate 
Table 1 Variables and parameters

\begin{tabular}{|c|c|c|c|c|}
\hline & \multirow[t]{2}{*}{ Symbol } & \multirow[t]{2}{*}{ Description } & \multicolumn{2}{|l|}{ Value } \\
\hline & & & Embryo & Adult \\
\hline \multirow[t]{6}{*}{ Variables } & $A$ & Expression of transcription factor Hnf6 & 1 & 0 \\
\hline & $x$ & Expression of transcription factor Ngn3 & 0 & 0 \\
\hline & Y & Expression of transcription factor Ptfla & 0 & 1 \\
\hline & Z & Expression of transcription factor $|s| 1$ & 0 & 0 \\
\hline & $\bar{x}$ & Average Ngn3 expression in neighboring cells & 0 & 0 \\
\hline & $\bar{Y}$ & Average Ptfla expression in neighboring cells & 0 & 1 \\
\hline \multirow[t]{9}{*}{ Parameters } & $a$ & Strength of lateral inhibition $X \vdash \dashv X$ & 1000 & \\
\hline & $b$ & Strength of lateral stabilization $Y \leftrightarrow Y$ & 2000 & \\
\hline & $c$ & Strength of inhibition $X \dashv Y$ and $Z \dashv Y$ & 500 & \\
\hline & 9 & Strength of induction $A \rightarrow X$ and $A \rightarrow Y$ & $10^{-4}$ & \\
\hline & $r$ & Strength of inhibition $Y \dashv A$ and $Z \dashv A$ & 100 & \\
\hline & s & Strength of autoactivation $Z \rightarrow Z$ & 50 & \\
\hline & $n$ & Hill coefficient, nonlinearity of reactions & 3 & \\
\hline & $\eta_{x}$ & Noise amplitude on $X$ & $10^{-3}$ & \\
\hline & $\eta_{y}$ & Noise amplitude on $Y$ & $10^{-3}$ & \\
\hline
\end{tabular}

Parameters and initial conditions of the mathematical model (equation 1-4). Parameter values are chosen identical for embryonic and adult conditions, configured with different initial conditions.

$(Z \approx 1)$ are mutually exclusive. For brevity, in the presentation of the results below, $Y^{+}$cells are acinar, $X^{+}$cells are islet progenitors, and $Z^{+}$cells are islet cells.

The states and (in)stabilities of the above model were studied using bifurcation analysis. Numerical simulation of a hexagonal lattice of cells was performed to study the spatiotemporal dynamics at the tissue scale. Analysis and numerical simulation were performed using GRIND (phase plane analysis) [47], XPPAUT (bifurcation analysis) [48] and our modeling environment Morpheus (lattice simulations) [49]. The stochastic differential equations were solved using the $2^{\text {nd }}$ order Heun-Maruyama method with time step size $d t=0.02$. The model description for lattice simulations in Morpheus is available as Additional file 1.

\section{Results}

\section{Multistability of acinar and islet cell fates}

Cell fates are characterized by stable patterns of gene expression. Whether a set of interacting genes is able to reach one or more stable states depends on their interaction topology as well as on the strengths of interaction. To investigate the cell fates that can appear in our model, we studied the existence of stable states and their dependence on parameter values for lateral signaling by performing a bifurcation analysis.

Due to lateral signaling, the fates of individual cells depend on the states of neighboring cells. Therefore, we analyzed a system of three cells representing a minimal tissue that is able to show all possible configurations present in larger systems (the mixed state does not occur for less than 3 cells). To study how the stability of cell fates changes while varying the strength of the lateral stabilization mechanism $b$, we recorded the summed expression level of exocrine factor $Y$. This reduces the high-dimensional state space to a single dimension and provides information on cell fates as well as their spatial pattern. The solid lines in the bifurcation diagram in Figure 2A show that $Y$ expression has three stable states over a wide range of parameter values. For these values of $b$, the three cells can have either acinar fates $(Y=3)$, islet cell fates $(Y=0)$ or have mixed fates $(Y=2)$, depending on initial conditions or history of gene expression.

This multistability of acinar and islet cell fates has several interesting consequences. The key observation is that a critical value $b_{c}$ exists, below which the stable steady state for the acinar fate disappears, while the islet cell fate remains stable. Thus, loss of the stabilizing effect of lateral signaling effectively moves the system towards a region in parameter space where the acinar cell fate no longer exists. Therefore, upon such a change in parameter values, acinar cells lose their exocrine markers and dedifferentiate spontaneously. In the presence of lateral inhibition (Figure 2A) cells adopt a multipotent progenitor-like fate. This state is stable against perturbations in $Y$, but unstable against perturbations in $X$, which implies that noise on $X$ can change this state. If lateral stabilization is recovered at this multipotent stage, the system moves towards a steady state with mixed acinar and islet cell fates, recapitulating the cell fate decision and spatial pattern observed 





during pancreas development [39]. If, however, disruption of lateral stabilization continues, cells differentiate into the islet cell lineage. After completing the lineage conversion, the islet fate is stable in the sense that recovery of lateral stabilization does not reverse conversion.

Interestingly, the bifurcation analysis shows a different behavior in the absence of lateral inhibition (Figure 2B). In this case, multipotent progenitor-like steady state does not exist. This implies that acinar cells cannot dedifferentiate towards a progenitor-like state upon loss of lateral stabilization. Instead, cells undergo direct lineage conversion from the acinar to the islet lineage, rather than passing through a state of multipotency.

In conclusion, bifurcation analysis reveals (1) that lateral stabilization accommodates multistability of the acinar and islet cell states, (2) that transient loss of lateral stabilization can cause the conversion of acinar to islet cells and (3) that concomitant suppression of lateral inhibition leads to direct conversion, bypassing the multipotent progenitor-like state. Yet, bifurcation analysis does not provide insight into the spatiotemporal dynamics for which we next turn to numerical simulations.

\section{Cell fate decision and patterning during pancreas development}

Cells undergoing acinar-to-islet cell conversion transiently express various factors and activate signaling pathways normally only observed during development ( $P d x 1$, Hnf6, Ngn3, Notch, Dll1) [21,23]. This suggests that at least a part of the developmental regulatory network is reactivated [16] and that cell fate decisions during organogenesis and cell type conversion are governed by the same regulatory mechanisms. Under this assumption, the model proposed here for acinar-to-islet cell conversion is expected to reproduce the cell fate decision between the exocrine or endocrine lineage during embryonic development.

To test whether the proposed model holds for the conditions during embryonic development, we simulated the model using initial conditions that represent the gene expression in early pancreatic progenitor cells. In the mouse, the inductive factors $H n f 6$ and $H n f 1 \beta$, that act upstream of lineage-associated factors Ngn3 and Ptfla, are first detected around E9 [38]. At this stage, Ngn3 and Ptf1a themselves are not yet expressed. Accordingly, the early embryonic state is accounted for in our model by the homogeneous expression of $A$ (Table 1 ).

Figure $3 \mathrm{~B}$ shows that during simulation, $A$ activates the expression of both $X$ and $Y$. For a transient period, these factors are co-expressed in all cells at low or intermediate levels of expression. The "promiscuous" co-expression is typical of multipotent progenitor cells and is also observed in pancreatic progenitors [40]. During this phase, mutual inhibition between cells maintains a low-level expression and thereby suppresses differentiation into either lineage, similar to the role of Notch signaling in pancreatic development known as "suppressive maintenance" [50]. After noise introduces variation in $X$ expression between cells, these differences become amplified by lateral inhibition and result in a divergence of $X$ expression. Factor $X$ activates islet cell differentiation by activating $Z$ and is only transiently expressed itself, as is known for $N g n 3$. Reversely, in the $X^{-}$surrounding cells, $Y$ is no longer inhibited and is upregulated. Through lateral stabilization, $Y^{+}$cells induce the expression of $Y$ in neighboring progenitor cells (with low $Y$ expression) which results in wave propagation, in a process traditionally known as homeogenetic induction [51]. Maturation into either lineage results in suppression of upstream factor $A$ which leads to the downregulation of the pro-endocrine factor $X$, while $Y$ is maintained by lateral stabilization. In line with experimental observations, both factors (Hnf6 and Ngn3) are not expressed after the cell fate decision and in the adult pancreas.

Interestingly, the spatial patterns generated by the model are also in line with reports of the scattered distribution of nascent islet cells in the early pancreatic epithelium [52]. The combination of lateral inhibition (creating an alternating pattern of acinar and islet cells) with lateral stabilization (creating homogeneous fields of acinar cells) results in the establishment of a scattered spatial distribution of endocrine cells in a mainly exocrine tissue (see Figure 3C) [39].

In short, under initial conditions representing early pancreas development, the key features of gene expression and patterning in the developing pancreas are reproduced by the model: (1) promiscuous expression of the lineage-associated factors Ngn3 and Ptfla, (2) the transient expression of the pro-endocrine factor Ngn3 and (3) the scattered spatial patterning of committed islet cells.

\section{Loss of lateral stabilization causes sequential conversion}

To understand the dynamics of acinar-to-islet cell conversion upon loss of lateral stabilization, simulated cells were initialized with an acinar-like gene expression profile in which only the exocrine factor $Y$ is expressed (see Table 1). The system was initialized with lateral stabilization strength $b>b_{c}$ to ensure the stability of the acinar-like state under these conditions. After a given period, lateral stabilization was lost, $b=0$, marking $t=0$.

As shown in Figure 3B', the acinar state is stable as long as lateral stabilization strength $b>b_{c}$, representing intact acinar tissue. However, immediately following the loss of lateral stabilization, cells lose the expression of exocrine marker $Y$. The lack of the maturation factor $Y$ leads to the re-activation of the upstream factor $A$. Since $A$ induces low levels of both $X$ and $Y$, at this stage, the expression pattern is identical to the early embryonic 




situation. Thus, loss of lateral stabilization causes cells to return towards the multipotent progenitor-like cell state. If the absence of lateral stabilization continues, the subsequent dynamics differ from the embryonic cell fate decision discussed above. Specifically, nascent islet cells arise in an alternating spatial pattern as a result of lateral inhibition between $X^{+}$cells (Figure 3C). Yet, this pattern is not stable. After a cell has committed to the islet lineage by transactivating the endocrine marker $Z$, it looses expression of $X$. Therefore, cells adjacent to endocrine $Z^{+}$cells are no longer inhibited and will start to express $X$ themselves. As a result, some of the neighboring cells also commit to the endocrine lineage, after which the process is repeated. This step-wise conversion of cells within the tissue results in a complex spatiotemporal patterning process (Figure 3C'). Under 
these idealized conditions, eventually all cells commit to the islet cell lineage. If, however, lateral stabilization is recovered before cells have redifferentiated, the cell type conversion is arrested which significantly decreases the efficiency of conversion (data not shown). Recovery does not revert newly committed islet cells back to acinar fate, since the islet cell state is stable, independent of lateral stabilization.

These results are in line with in vitro experiments showing spontaneous dedifferentiation upon enzymatic disassociation and disruption of cadherin-mediated cell-cell adhesion [13,20-22]. Furthermore, these results suggest that acinar-to-islet cell conversion ensuing loss of lateral stabilization is a relatively slow process due to the fact that lateral inhibition prevents neighboring cells from completing transdifferentiation simultaneously.

\section{Loss of lateral inhibition accelerates conversion}

In the embryo, disruption of the Notch signaling pathway is known to cause precocious endocrine commitment [24]. Moreover, its inhibition in adult acinar cells can dramatically increase the efficiency of acinar-to-islet cell type conversion [23]. Since one of the roles of Notch signaling in the developing pancreas is lateral inhibition, we examined the dynamics of the model after a sudden loss of lateral inhibition. As before, we used the acinar-like initial conditions (Table 1), but now both lateral stabilization and lateral inhibition were lost, $a=b=0$, after a given period.

Immediately ensuing this manipulation, $Y$ expression rapidly decreases, causing the reactivation of $A$ expression, as described before. However, in this case, the dedifferentiated cells do not return to a multipotent state with "promiscuous" co-expression. Instead, all cells simultaneously upregulate the pro-endocrine factor $X$ since they are not inhibited by their neighbors (see Figure 3B"). Finally, after the transactivation of $Z$ by $X$, the factors $A$ and $X$ are suppressed again, leading to an adult islet fate in all cells. Compared to the loss of stabilization, the additional loss of lateral inhibition results in a much faster dynamical process of lineage conversion. In line with results obtained in vitro [23], our model shows that concomitant inhibition of lateral inhibition accelerates acinar-toislet conversion. Here, this observation is explained by the fact that, under disruption of lateral inhibition, the unstable steady state representing the multipotent progenitor state does not exist, as predicted by bifurcation analysis (Figure 2B).

Note that disruption of lateral inhibition alone $(a=0$, $b>b_{c}$ ) does not affect acinar cell stability, since the pro-endocrine factor $X$, which is involved in this feedback between cells, is not expressed in adult acinar cells. Therefore, without loss of lateral stabilization, cells maintain their acinar identity.

\section{Cell density affects conversion efficiency}

If the disruption of contact-mediated signaling influences the efficiency of acinar-to-islet cell conversion, loss of physical contacts between cells could replace molecular manipulation. To study the effect of cell-cell contacts, we performed simulations with varying densities of acinar cells. As expected, it was found that conversion efficiency increases with decreasing cell density (see Figure 4). For extreme cases, the reason behind this is evident. At high densities, most cells have many contacts with neighboring acinar cells and the stabilizing positive feedback prevents their dedifferentiation. Conversely, at low density, most cells are isolated and do not receive stabilizing (or inhibiting) cell-cell signals. Consequently, these cells can complete transdifferentiation. However, for more realistic intermediate cases in which cells are part of small aggregates, the situation becomes nontrivial. Here, the probability of cell conversion depends on both size and shape of the cellular aggregate. Although cells in larger clusters are generally more stable, this stability also depends on the spatial arrangement of cells in the aggregate (Figure 4C). Because the dedifferentiation of one cell weakens the stability of its neighboring cells, waves of dedifferentiation and conversion can propagate through the aggregate, depending on the average number of neighboring cells that reflects both density and configuration of a cell cluster.

These results show that, in the context of our model, the size and the structure of cellular aggregates affects the efficiency of lineage conversion. This implies that the degree of dissociation of acini by enzymatic digestion is predicted to have large impact on islet cell yield. More generally, the use of low cell densities or, alternatively, inhibition of reaggregation of cells, is predicted to increase the efficiency of acinar-to-islet cell conversion in vitro.

\section{Discussion and conclusion}

Forcing adult cells to change lineage by altering the microenvironment offers an alternative to the more risky method of virus-mediated nuclear reprogramming $[6,7]$. Apart from identifying of specific growth factors and small molecules that induce a particular lineage conversion in vitro, recent work in this direction also demonstrates that contact-mediated lateral signals are key regulators of cell fate maintenance and multipotency [8-14]. For instance, it was found that loss of cell-cell adhesion between adult acinar cells of the pancreas causes dedifferentiation and enables their conversion into islet cells $[13,20]$. Together with more recent data showing that inhibition of contact-mediated Notch signaling between these cells significantly improves conversion efficiency [23], this demonstrates that lateral signals are important regulators of cell fate control in the pancreas. However, despite the identification of a myriad of transcription factors 


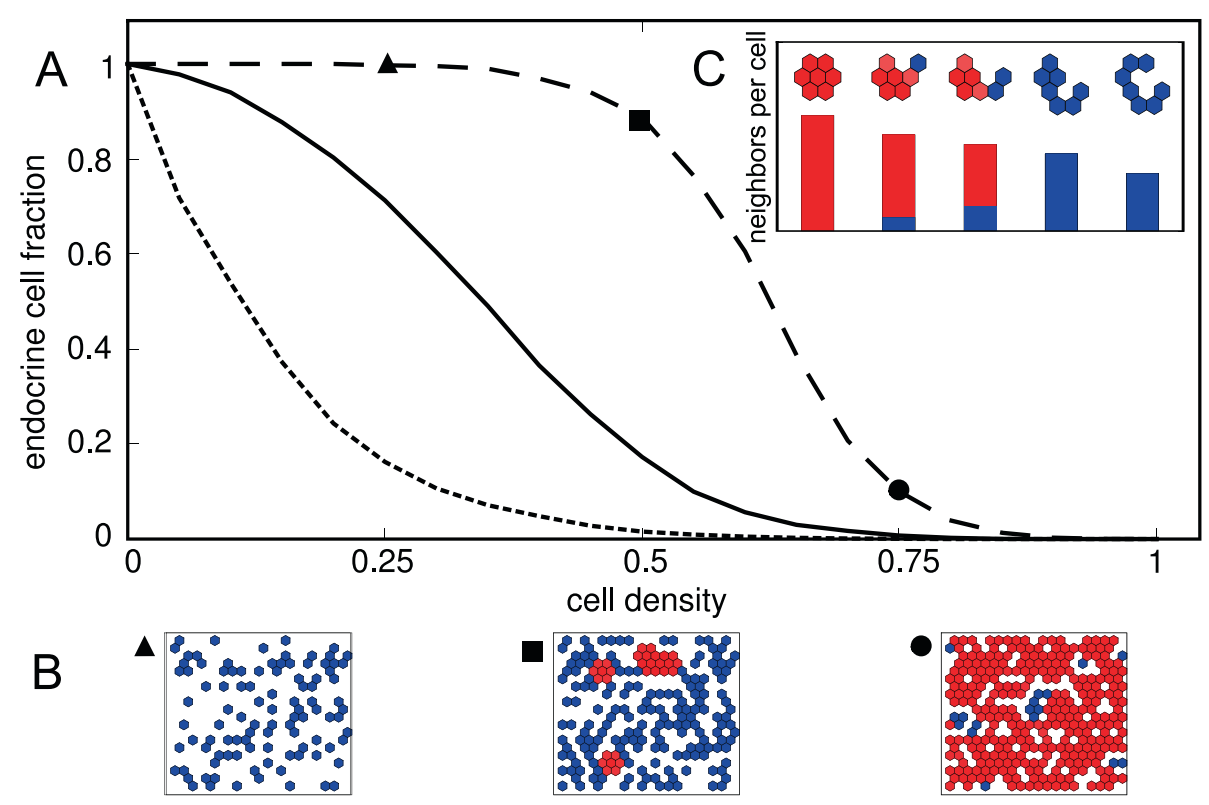

Figure 4 Cell density affects conversion efficiency. (A) The fraction of acinar cells that convert to islet cells increases with decreasing cell density, as shown for three values of lateral stabilization strength, $b=1$ (dotted), $b=0.1$ (solid), $b=0.01$ (dashed). (B) Examples of the steady-state situation (acinar cells in red and islet cells in blue) for three different cell densities as indicated on the dashed curve $(b=0.01$, densities $0.25,0.50$ and 0.75). Note the presence of compact clusters of stable acinar cells in the middle panel. (C) Shape of cellular aggregates determines the efficiency of conversion. A decrease in compactness, measured as average neighbors per cell, increases the islet cell yield. Parameters as in Table 1, $b$ as indicated.

and signaling molecules involved in lineage conversion, a coherent understanding of the roles of contact-mediated lateral signals in this process is lacking.

A systems biological approach can help to make sense of complex dynamic regulatory networks through the use of mathematical models and dynamical system theory $[25,26]$. In previous work, we have adopted this approach to construct a hierarchical multi-attractor model of the pancreatic transcriptional network to understand and propose nuclear reprogramming strategies [30]. In the present study, instead, we have focused on the role of contact-mediated signals on conversion dynamics to predict the outcomes of microenvironment-induced strategies for transdifferentiation.

We have presented a mathematical model that combines gene regulation and lateral signaling in pancreatic cells. We have demonstrated that the crosstalk of two contactmediated signaling mechanisms (lateral inhibition and lateral stabilization) causes multistability in which both acinar and islet cell fates are stable. Our discovery of the multistable state explains why conversion of acinar to islet cells is possible, even without genetic manipulation. Inhibition of lateral stabilization destabilizes of acinar cells and causes the dedifferentiation of acinar cells towards a progenitor-like multipotent state and invokes the subsequent step-wise conversion towards an islet cell fate. Moreover, we have shown that additional loss of lateral inhibition accelerates the conversion dynamics because, under these conditions, cells undergo a direct lineage switching, without passing through a multipotent state.

Altogether, our results provide a theoretical background to understand studies of acinar-to-islet cell conversion in vitro $[13,18-20,23]$. Moreover, this study offers several testable predictions, such as the impact of cell density, that may be used to improve the efficiency of microenvironment-induced conversion strategies. More generally, our results demonstrate that the crosstalk of multiple lateral signaling mechanisms can generate counterintuitive effects controlling cell fate stability as well as spatial patterning, which deserve further investigation. Furthermore, this study underscores that the identity of cells depends on the multicellular context of the tissue. Therefore, considering the feedback from the tissue level to the genetic level is important in order to understand how cell fate stability and plasticity are controlled.

\section{Additional files}

Additional file 1: Morpheus XML model description file. XML file to run lattice simulations in the modeling environment Morpheus [49], which can be downloaded at http://imc.zih.tu-dresden.de/wiki/morpheus. The model is configured to reproduce the simulations of conversion by loss of

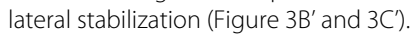

Additional file 2: Spatial and temporal dynamics: Development. Movie showing spatial and temporal dynamics during development, as in 
Figure $3 B$ and $3 C$. Left panels show a spatial dynamics in lattice simulation with colors indicating expression levels of $A, X, Y$ and $Z$. Right panels show corresponding gene expression of the same factors over time. Lattice simulation performed with our own modeling software Morpheus [49].

Additional file 3: Spatial and temporal dynamics: Conversion by loss of lateral stabilization. Movie showing spatial and temporal dynamics during adult lineage conversion, as in Figure $3 \mathrm{~B}^{\prime}$ and $3 \mathrm{C}^{\prime}$. Left panels show a spatial dynamics in lattice simulation with colors indicating expression levels of $A, X, Y$ and $Z$. Right panels show corresponding gene expression of the same factors over time. Lattice simulation performed with our own modeling software Morpheus [49].

Additional file 4: Spatial and temporal dynamics: Conversion by loss of lateral signaling. Movie showing spatial and temporal dynamics during adult lineage conversion, as in Figure 3B" and 3C". Left panels show a spatial dynamics in lattice simulation with colors indicating expression levels of $A, X, Y$ and $Z$. Right panels show corresponding gene expression of the same factors over time. Lattice simulation performed with our own modeling software Morpheus [49].

\section{Competing interests}

The authors declare that they have no competing interests.

\section{Authors' contributions}

WdB conceived the study, constructed the mathematical model, participated in its analysis and drafted the manuscript. RZ participated in modeling and performed bifurcation analysis and numerical simulation and helped to draft the manuscript. LB participated in the design of the study as well as its coordination and helped in analysis and drafting the manuscript. All authors read and approved the final manuscript.

\section{Acknowledgements}

The authors thank Joseph Xu Zhou, Anja Voß-Böhme, and Andreas Deutsch for fruitful discussions and acknowledge support by BMBF under grant no. 0315259

\section{Author details}

${ }^{1}$ Center for Information Services and High Performance Computing, Technische Universität Dresden, Dresden, 01062, Germany. ${ }^{2}$ Institute of Biotechnology, University of Helsinki, PO Box 56, Helsinki FIN-00014, Finland.

Received: 10 October 2012 Accepted: 4 July 2013

Published: 13 August 2013

\section{References}

1. Stadtfeld M, Hochedlinger K: Induced pluripotency: history, mechanisms, and applications. Genes Dev 2010, 24(20):2239-2263. http://dx.doi.org/10.1101/gad.1963910.

2. Plath K, Lowry WE: Progress in understanding reprogramming to the induced pluripotent state. Nat Rev Genet 2011, 12(4):253-265. http://dx. doi.org/10.1038/nrg2955.

3. Cherry $A B C$, Daley GQ: Reprogramming cellular identity for regenerative medicine. Cell 2012, 148(6):1110-1122. http://dx.doi.org/ 10.1016/j.cell.2012.02.031

4. Sancho-Martinez I, Baek SH, Izpisua Belmonte JC: Lineage conversion methodologies meet the reprogramming toolbox. Nat Cell Biol 2012 14(9):892-899. http://dx.doi.org/10.1038/ncb2567.

5. Takahashi K, Yamanaka S: Induction of pluripotent stem cells from mouse embryonic and adult fibroblast cultures by defined factors. cell 2006, 126(4):663-676.

6. Cohen $D E$, Melton $D$ : Turning straw into gold: directing cell fate for regenerative medicine. Nat Rev Genet 2011, 12(4):243-252. http://dx. doi.org/10.1038/nrg2938.

7. Lin J, Li MR, Ti DD, Chen MX, Hao HJ, Zhao YL, Fu XB, Han WD: Microenvironment-evoked cell lineage conversion: Shifting the focus from internal reprogramming to external forcing. Ageing Res Rev 2012. http://dx.doi.org/10.1016/j.arr.2012.04.002.

8. $L i L$, Bennett $S A L$, Wang $L$ : Role of E-cadherin and other cell adhesion molecules in survival and differentiation of human pluripotent stem cells. Cell Adh Migr 2012, 6:59-70. http://dx.doi.org/10.4161/cam.19583.
9. Redmer T, Diecke S, Grigoryan T, Quiroga-Negreira A, Birchmeier W, Besser D: E-cadherin is crucial for embryonic stem cell pluripotency and can replace $\mathrm{OCT} 4$ during somatic cell reprogramming. $E M B O R e p$ 2011, 12(7):720-726. http://dx.doi.org/10.1038/embor.2011.88.

10. Chen T, Yuan D, Wei B, Jiang J, Kang J, Ling K, Gu Y, Li J, Xiao L, Pei G: E-cadherin-mediated cell-cell contact is critical for induced pluripotent stem cell generation. Stem Cells 2010, 28(8):1315-1325. http://dx.doi.org/10.1002/stem.456

11. Zhang J, Woodhead GJ, Swaminathan SK, Noles SR, McQuinn ER, Pisarek AJ, Stocker AM, Mutch CA, Funatsu N, Chenn A: Cortical neural precursors inhibit their own differentiation via $\mathrm{N}$-cadherin maintenance of beta-catenin signaling. Dev Cell 2010, 18(3):472-479. http://dx.doi.org/10.1016/j.devcel.2009.12.025.

12. Soncin F, Mohamet L, Eckardt D, Ritson S, Eastham AM, Bobola N, Russell A, Davies S, Kemler R, Merry CLR, Ward CM: Abrogation of E-cadherin-mediated cell-cell contact in mouse embryonic stem cells results in reversible LIF-independent self-renewal. Stem Cells 2009, 27(9):2069-2080. http://dx.doi.org/10.1002/stem.134.

13. Minami K, Okano H, Okumachi A, Seino S: Role of cadherin-mediated cell-cell adhesion in pancreatic exocrine-to-endocrine transdifferentiation. J Bio/ Chem 1375, 283(20):3-13761. http://dx.doi org/10.1074/jbc.M710034200.

14. Zhu L, Tran T, Rukstalis JM, Sun P, Damsz B, Konieczny SF: Inhibition of Mist 1 homodimer formation induces pancreatic acinar-to-ductal metaplasia. Mol Cell Biol 2004, 24(7):2673-2681.

15. Efrat S: Stem Cell Therapy for Diabetes. New York: Humana Press; 2010

16. Baeyens L, Rooman I, Bouwens L: Stem Cell Therapy for Diabetes. chap. Generation of beta cells from acinar cells. Edited by Efrat, S. New York: Humana Press; 2010

17. Zhou Q, Brown J, Kanarek A, Rajagopal J, Melton DA: In vivo reprogramming of adult pancreatic exocrine cells to beta-cells. Nature 2008, 455(7213):627-632. http://dx.doi.org/10.1038/nature07314.

18. Rooman I, Heremans $Y$, Heimberg H, Bouwens L: Modulation of rat pancreatic acinoductal transdifferentiation and expression of PDX-1 in vitro. Diabetologia 2000, 43(7):907-914. http://dx.doi.org/10.1007/ s001250051468.

19. Song KH, Ko SH, Ahn YB, Yoo SJ, Chin HM, Kaneto H, Yoon KH, Cha BY, Lee KW, Son HY: In vitro transdifferentiation of adult pancreatic acinar cells into insulin-expressing cells. Biochem Biophys Res Commun 2004, 316(4):1094-1100. http://dx.doi.org/10.1016/j.bbrc.2004.02.153.

20. Baeyens L, Breuck SD, Lardon J, Mfopou JK, Rooman I, Bouwens L: In vitro generation of insulin-producing beta cells from adult exocrine pancreatic cells. Diabetologia 2005, 48:49-57. http://dx.doi.org/10.1007/ s00125-004-1606-1.

21. Minami K, Okuno M, Miyawaki K, Okumachi A, Ishizaki K, Oyama K, Kawaguchi M, Ishizuka N, Iwanaga T, Seino S: Lineage tracing and characterization of insulin-secreting cells generated from adult pancreatic acinar cells. Proc Natl Acad Sci U S A 2005, 102(42):15116-15121. http://dx.doi.org/10.1073/pnas.0507567102.

22. Baeyens L, Bonné S, German MS, Ravassard P, Heimberg H, Bouwens L: Ngn3 expression during postnatal in vitro beta cell neogenesis induced by the JAK/STAT pathway. Cell Death Differ 2006 13(11):1892-1899. http://dx.doi.org/10.1038/sj.cdd.4401883.

23. Baeyens L, Bonné S, Bos T, Rooman I, Peleman C, Lahoutte T, German M, Heimberg $H$, Bouwens $L$ : Notch signaling as gatekeeper of rat acinar-to-beta-cell conversion in vitro. Gastroenterology 2009, 136(5):1750-1760.e13. http://dx.doi.org/10.1053/j.gastro.2009.01.047.

24. Apelqvist A, Li H, Sommer L, Beatus P, Anderson DJ, Honjo T, de Angelis $\mathrm{MH}$, Lendahl $\mathrm{U}$, Edlund $\mathrm{H}$ : Notch signalling controls pancreatic cell differentiation. Nature 1999, 400(6747):877-881. http://dx.doi.org/10. 1038/23716

25. Huang S, Guo YP, May G, Enver T: Bifurcation dynamics in lineage-commitment in bipotent progenitor cells. Dev Biol 2007 305(2):695-713. http://dx.doi.org/10.1016/j.ydbio.2007.02.036.

26. Macarthur BD, Ma'ayan A, Lemischka IR: Systems biology of stem cell fate and cellular reprogramming. Nat Rev Mol Cell Biol 2009, 10(10):672-681. http://dx.doi.org/10.1038/nrm2766

27. Enver T, Pera M, Peterson C, Andrews PW: Stem cell states, fates, and the rules of attraction. Cell Stem Cell 2009, 4(5):387-397. http://dx.doi. org/10.1016/j.stem.2009.04.011. 
28. Schittler D, Hasenauer J, Allgöwer F, Waldherr S: Cell differentiation modeled via a coupled two-switch regulatory network. Chaos 2010 20. http://dx.doi.org/10.1063/1.3505000.

29. Glauche I, Cross M, Loeffler M, Roeder I: Lineage specification of hematopoietic stem cells: mathematical modeling and biological implications. Stem Cells 2007, 25(7):1791-1799. http://dx.doi.org/10. 1634/stemcells.2007-0025.

30. Zhou JX, Brusch L, Huang S: Predicting pancreas cell fate decisions and reprogramming with a hierarchical multi-attractor model. PLoS One 2011, 6(3):e14752. http://dx.doi.org/10.1371/journal.pone. 0014752 .

31. Gradwohl G, Dierich A, LeMeur M, Guillemot F: Neurogenin3 is required for the development of the four endocrine cell lineages of the pancreas. Proc Natl Acad Sci U S A 2000, 97(4):1607-1611.

32. Jensen J, Pedersen EE, Galante P, Hald J, Heller RS, Ishibashi M, Kageyama R, Guillemot F, Serup P, Madsen OD: Control of endodermal endocrine development by Hes-1. Nat Genet 2000, 24:36-44. http://dx. doi.org/10.1038/71657.

33. Lewis J: Notch signalling and the control of cell fate choices in vertebrates. Semin Cell Dev Biol 1998, 9(6):583-589. http://dx.doi.org/10. 1006/scdb.1998.0266.

34. Collier JR, Monk NA, Maini PK, Lewis JH: Pattern formation by lateral inhibition with feedback: a mathematical model of delta-notch intercellular signalling. J Theor Bio/ 1996, 183(4):429-446. http://dx.doi. org/10.1006/jtbi.1996.0233.

35. Ahlgren U, Pfaff SL, Jessell TM, Edlund T, Edlund H: Independent requirement for ISL1 in formation of pancreatic mesenchyme and islet cells. Nature 1997, 385(6613):257-260. http://dx.doi.org/10.1038/ 385257a0.

36. Krapp A, Knöfler M, Frutiger S, Hughes GJ, Hagenbüchle O, Wellauer PK: The p48 DNA-binding subunit of transcription factor PTF1 is a new exocrine pancreas-specific basic helix-loop-helix protein. $E M B O \mathrm{~J}$ 1996, 15(16):4317-4329.

37. Zecchin E, Mavropoulos A, Devos N, Filippi A, Tiso N, Meyer D, Peers B, Bortolussi $M$, Argenton F: Evolutionary conserved role of ptf1a in the specification of exocrine pancreatic fates. Dev Biol 2004, 268:174-184. http://dx.doi.org/10.1016/j.ydbio.2003.12.016.

38. Kawaguchi Y, Cooper B, Gannon M, Ray M, MacDonald RJ, Wright CVE: The role of the transcriptional regulator Ptf1a in converting intestinal to pancreatic progenitors. Nat Genet 2002, 32:128-134. http://dx.doi.org/10.1038/ng959.

39. de Back W, Zhou JX, Brusch L: On the role of lateral stabilization during early patterning in the pancreas. J R Soc Interface 2013 10(79):20120766. http://dx.doi.org/10.1098/rsif.2012.0766.

40. Chiang MK, Melton DA: Single-cell transcript analysis of pancreas development. Dev Cell 2003, 4(3):383-393.

41. Sander M, Sussel L, Conners J, Scheel D, Kalamaras J, Cruz FD, Schwitzgebel V, Hayes-Jordan A, German M: Homeobox gene Nkx6. lies downstream of $\mathbf{N k x 2 . 2 ~ i n ~ t h e ~ m a j o r ~ p a t h w a y ~ o f ~ b e t a - c e l l ~}$ formation in the pancreas. Development 2000, 127(24):5533-5540.

42. Wilson ME, Scheel D, German MS: Gene expression cascades in pancreatic development. Mech Dev 2003, 120:65-80.

43. Schaffer $A E$, Freude $K K$, Nelson SB, Sander M: Nkx6 transcription factors and Ptf1a function as antagonistic lineage determinants in multipotent pancreatic progenitors. Dev Cell 2010, 18(6):1022-1029. http://dx.doi.org/10.1016/j.devcel.2010.05.015.

44. Jacquemin P, Durviaux SM, Jensen J, Godfraind C, Gradwohl G, Guillemot F, Madsen OD, Carmeliet P, Dewerchin M, Collen D, Rousseau GG, Lemaigre FP: Transcription factor hepatocyte nuclear factor 6 regulates pancreatic endocrine cell differentiation and controls expression of the proendocrine gene ngn3. Mol Cell Biol 2000, 20(12):4445-4454.

45. Haumaitre C, Barbacci E, Jenny M, Ott MO, Gradwohl G, Cereghini S: Lack of TCF2/vHNF1 in mice leads to pancreas agenesis. Proc Natl Acad SciU SA 2005, 102(5):1490-1495. http://dx.doi.org/10.1073/pnas.0405776102.

46. Maestro MA, Boj SF, Luco RF, Pierreux CE, Cabedo J, Servitja JM, German MS, Rousseau GG, Lemaigre FP, Ferrer J: Hnf6 and Tcf2 (MODY5) are linked in a gene network operating in a precursor cell domain of the embryonic pancreas. Hum Mol Genet 2003, 12(24):3307-3314. http://dx. doi.org/10.1093/hmg/ddg355.
47. de Boer R, Pagie L: GRIND: Great Integrator Differential Equations. http:// bioinformatics.bio.uu.nl/rdb/grind.html.

48. Ermentrout B: XPPAUT:X-windows Phase Plane plus Auto. http://www math.pitt.edu/ bard/xpp/xpp.html.

49. Starruß J, de Back W, Deutsch A: Morpheus: modeling and simulation environment for multicellular systems. http://imc.zih.tu-dresden.de/ wiki/morpheus

50. Norgaard GA, Jensen JN, Jensen J: FGF10 signaling maintains the pancreatic progenitor cell state revealing a novel role of Notch in organ development. Dev Biol 2003, 264(2):323-338.

51. Mangold O, Spemann H: Über Induktion von Medullarplatte durch Medullarplatte im jüngeren Keim, ein Beispiel homöogenetischer oder assimilatorischer Induktion. Wilhelm Roux Arch. EntwMech. Org 1927, 111:341-422.

52. Jørgensen MC, Ahnfelt-Rønne J, Hald J, Madsen OD, Serup P, Hecksher-Sørensen J: An illustrated review of early pancreas development in the mouse. Endocr Rev 2007, 28(6):685-705. http://dx doi.org/10.1210/er.2007-0016

doi:10.1186/1752-0509-7-77

Cite this article as: de Back et al.: Transdifferentiation of pancreatic cells by loss of contact-mediated signaling. BMC Systems Biology 2013 7:77.

\section{Submit your next manuscript to BioMed Central and take full advantage of:}

- Convenient online submission

- Thorough peer review

- No space constraints or color figure charges

- Immediate publication on acceptance

- Inclusion in PubMed, CAS, Scopus and Google Scholar

- Research which is freely available for redistribution 